\title{
EFFICACY OF TRANSFORAMINAL EPIDURAL STEROID INJECTION IN LUMBOSACRAL RADICULOPATHY
}

\author{
Saheel Majid ${ }^{1}$, Dinesh K. Yadav², Suhail M. Vakil3 , Zameer Ali ${ }^{4}$, Tauseef A. Bhat ${ }^{5}$, Ayaz Ali', Shafaqat Rashid ${ }^{7}$, Shabir A. Dhar ${ }^{8}$
}

${ }_{1}^{1}$ Associate Professor, Department of Orthopaedics, SKIMS Medical College, Bemina, Srinagar.

${ }_{2}^{2}$ ost Graduate, Department of Orthopaedics, SKIMS Medical College, Bemina, Srinagar.

${ }^{3}$ Registrar, Department of Orthopaedics, SKIMS Medical College, Bemina, Srinagar.

${ }^{4}$ Registrar, Department of Orthopaedics, SKIMS Medical College, Bemina, Srinagar.

${ }^{5}$ Registrar, Department of Orthopaedics, SKIMS Medical College, Bemina, Srinagar.

${ }^{6}$ Registrar, Department of Orthopaedics, SKIMS Medical College, Bemina, Srinagar.

${ }^{7}$ Registrar, Department of Anaesthesia, SKIMS Medical College, Bemina, Srinagar.

${ }^{8}$ Assistant Professor, Department of Orthopaedics, SKIMS Medical College, Bemina, Srinagar.

\begin{tabular}{l} 
ABSTRACT \\
\hline BACKGROUND \\
Lumbosacral radiculopathy is a common medical and socioeconomic problem with a lifetime prevalence estimated to be around \\
40\%-60\%. In 1930, Evans reported that sciatica could be treated by epidural injection. The use of epidural corticosteroid injection \\
for the treatment of axial and radicular back pain was first reported in 1953. Lumbar Transforminal Epidural Steroid Injections \\
(TFESIs) are performed to provide symptomatic relief in patients with radicular pain. A transforaminal epidural steroid injection \\
(TFESI) using a small volume of local anaesthetic will anaesthetize the spinal nerve and also partially anaesthetize the dura, the \\
posterior longitudinal ligament, the intervertebral disc and facet joint. For these reasons, fluoroscopy-guided TFESI has become the \\
preferred approach to epidural space.
\end{tabular}

\section{AIMS AND OBJECTIVES}

To study the role of transforaminal epidural steroid injection in management of radiculopathy.

\section{SETTINGS AND DESIGN}

This prospective study was conducted in the Department of Orthopaedics, SKIMS Medical College and Hospital, Bemina, Srinagar, J and K, India, for a 2-year period from November 2012 to October 2014; 110 cases, both male and female in the age group of 20-60 years having back pain with radiculopathy of varied types and duration without neurodeficit were enrolled in the study.

\section{MATERIALS AND METHODS}

After selecting a patient for giving transforaminal block, we used a local anaesthetic ( $2 \%$ Xylocaine). Contrast media, e.g. Iohexol was used to demarcate the correct positioning of the needle. A spinal needle (20-25 gauge) and $5 \mathrm{~mL}$ syringe were used to deliver the drug.

\section{CONCLUSION}

Transforaminal epidural steroid injections with long acting anaesthetic is an excellent form of conservative treatment in management of low back ache with radicular pain. It is relatively safe, simple, economical and shortens the time of recovery from severe pain, avoids risks and complications of surgery and also avoids long periods of bed rest.

\section{KEYWORDS}

NSAID-Non-Steroidal Anti-Inflammatory Drugs, TFESI-Transforaminal Epidural Steroid Injection, SLRT-Straight Leg Raising Test, VAS-Visual Analogue Score, SNRB-Selective Nerve Root Block.

HOW TO CITE THIS ARTICLE: Majid S, Yadav DK, Vakil SM, et al. Efficacy of transforaminal epidural steroid injection in lumbosacral radiculopathy. J. Evolution Med. Dent. Sci. 2016;5(15):727-731, DOI: 10.14260/jemds/2016/167

\section{INTRODUCTION}

Low back pain combined with radicular pain remains one of the most challenging musculoskeletal problems for therapeutic management in modern society. ${ }^{1}$

This malady results from nerve root impingement and/or inflammation that causes neurologic symptoms in the

Financial or Other, Competing Interest: None.

Submission 06-01-2016, Peer Review 02-02-2016,

Acceptance 08-02-2016, Published 22-02-2016.

Corresponding Author:

Dr. Suhail Maqbool Vakil,

R/O: B-12, Budshah Nagar,

Natipora, Srinagar-190015.

Jammu \& Kashmir, India.

E-mail: suhailvakil1@yahoo.com

DOI: $10.14260 /$ jemds/2016/167 distribution of the affected nerve root(s). Lumbosacral radiculopathy is a common medical and socioeconomic problem with a lifetime prevalence estimated to be around $40 \%-60 \%{ }^{2,3,4}$ Several methods of treatment for radiculopathy have been discussed in literature. These include conservative methods like rest, manipulation, NSAIDS, opioids and surgeries like Laminectomy, Laminotomy and Fenestration procedures. The treating Orthopaedist is left with little room to manoeuvre between purely conservative and surgical methods.

In 1930, Evans reported that sciatica could be treated by epidural injection. The use of epidural corticosteroid injection for the treatment of axial and radicular back pain was first reported in 1953.5

Lumbar transforminal epidural steroid injections (TFESIs) are performed to provide symptomatic relief in 
patients with radicular pain. 6,7 Radicular pain manifests when adhesions and inflammation in the epidural space stimulate nerve roots. Steroid containing injections are thought to reduce pain due to their anti-inflammatory properties and membrane stabilising effects. They have also been proved to be effective as a non-surgical option.8,9 The goal is to deliver steroids and anaesthetics into the epidural space around the spinal nerves and other spinal structures. A transforaminal injection is an approach towards the epidural space via the intervertebral foramen where the spinal nerves exit.10,11,12,13 The epidural space has been accessed inferiorly through the caudal approach or posteriorly through the inter laminar approach.

A transforaminal epidural steroid injection (TFESI) using a small volume of local anaesthetic will anaesthetize the spinal nerve and also partially anaesthetize the dura, the posterior longitudinal ligament, the intervertebral disc and facet joint. ${ }^{14}$ For these reasons, fluoroscopy-guided TFESI has become the preferred approach to epidural space.

Fluoroscopically guided transforaminal injection serve as an important tool in the non-surgical management of lumbosacral radiculopathy secondary to herniated nucleus pulposus.

\section{AIMS AND OBJECTIVES}

To study the role of transforaminal epidural steroid injection in management of radiculopathy.

\section{MATERIALS AND METHODS}

This prospective study was conducted in the Department of Orthopaedics, SKIMS Medical College and Hospital, Bemina, Srinagar, J and K, India, for a 2-year period from November 2012 to October 2014; 110 cases, both male and female in the age group of 20-60 years having back pain with radiculopathy of varied types and duration without neurodeficit were enrolled in the study.

The patients were assessed in terms of gait, posture, onset, duration, radiation and character of pain. The patients were subjected to thorough history, physical examination and a detailed neurological examination. The patients underwent various clinical tests followed by radiological investigations like X-rays and MRI to support our diagnosis, which was formulated on clinical basis. Patients also underwent tests like Bleeding Time (BT), Clotting Time (CT) to rule out any bleeding disorders. All these tests were done on OPD basis and the patients did not require hospitalisation. The required block was given in Operation Theatre under $\mathrm{C}$-arm guidance.

\section{Inclusion Criteria}

1. Leg pain greater than back pain.

2. Symptoms greater than 6 weeks.

3. MRI documented herniated nucleus pulposus.

4. Less than $50 \%$ narrowing of the intervertebral foramen.

5. Constant radicular pain without sensory or motor deficit.

\section{Exclusion Criteria}

1. Back pain with neurodeficit.

2. Acute pain of less than 2 weeks' duration.

3. Any bleeding disorders.

4. Patient on anticoagulants.
5. Back pain due to massive disc.

6. Previous surgery.

7. Severe central or foraminal stenosis.

8. Progressive neurodeficit.

9. Prior epidural steroid injection.

\section{MATERIALS USED}

After selecting a patient for giving transforaminal block, we used a local anaesthetic ( $2 \%$ Xylocaine). Contrast media, e.g. Iohexol was used to demarcate the correct positioning of the needle. A spinal needle (20-25 gauge) and $5 \mathrm{~mL}$ syringe were used to deliver the drug.

\section{PROCEDURE}

The patient was placed prone on the radiolucent operative table. The area of injection was prepared with isopropyl alcohol and povidone-iodine several segments above and below the interspace to be injected. The patient was draped in a sterile fashion. Under antero-posterior fluoroscopic guidance, the target interspace was identified. The soft tissues over the lateral border and the midway between the two adjacent transverse processes at the target interspace were anaesthetized with Xylocaine 2\%. A 43/4 inch, 22-gauge spinal needle was taken and advanced within the anaesthetized soft tissue under fluoroscopy until contact was made with the lower edge of superior transverse process near its junction with superior articular process. The spinal needle was retracted $2-3 \mathrm{~mm}$ and redirected towards the base of appropriate pedicle and advanced slowly to the 6'o clock position of the pedicle under fluoroscopy. The $\mathrm{C}$-arm was adjusted to the lateral position to confirm the position. Then we returned C-arm to the AP view. The stylet was removed. $1 \mathrm{~mL}$ of non-ionic contrast was injected slowly to produce a perineurosheathogram. After an adequate dye pattern was observed, a $2 \mathrm{~mL}$ volume containing $1 \mathrm{~mL}$ of $2 \%$ preservative free Xylocaine and $1-2 \mathrm{~mL}$ of dexamethasone was injected.

The S1 nerve root when required was also injected using the transforaminal approach. After placing and preparing the patient as above, the C-arm was directed so that the fluoroscopic beam would be in a cephalocaudal and lateral to medial direction and the anterior and posterior S1 foramina are aligned. The soft tissues and dorsal aspect of sacrum were anaesthetized with $2-3 \mathrm{~mL}$ of $2 \%$ preservative free Xylocaine without epinephrine. A 22-gauge spinal needle was inserted and advanced within the anaesthetized soft tissue tract under fluoroscopy until contact was made with the posterior sacral bone slightly lateral and inferior to $\mathrm{S} 1$ pedicle. The spinal needle was walked off the sacrum into the posterior S1 foramen to the medial edge of pedicle. The $\mathrm{C}$-arm was adjusted to a lateral projection to confirm the position and then returned to the anteroposterior view. The stylet was removed; $1 \mathrm{~mL}$ of non-ionic contrast (Iohexol) was injected slowly to produce a perineurosheathogram. After an adequate dye pattern of S1 nerve root was obtained, a $2 \mathrm{~mL}$ volume containing $1 \mathrm{~mL}$ of $2 \%$ of preservative free Xylocaine and 1$2 \mathrm{~mL}$ of dexamethasone was injected. 


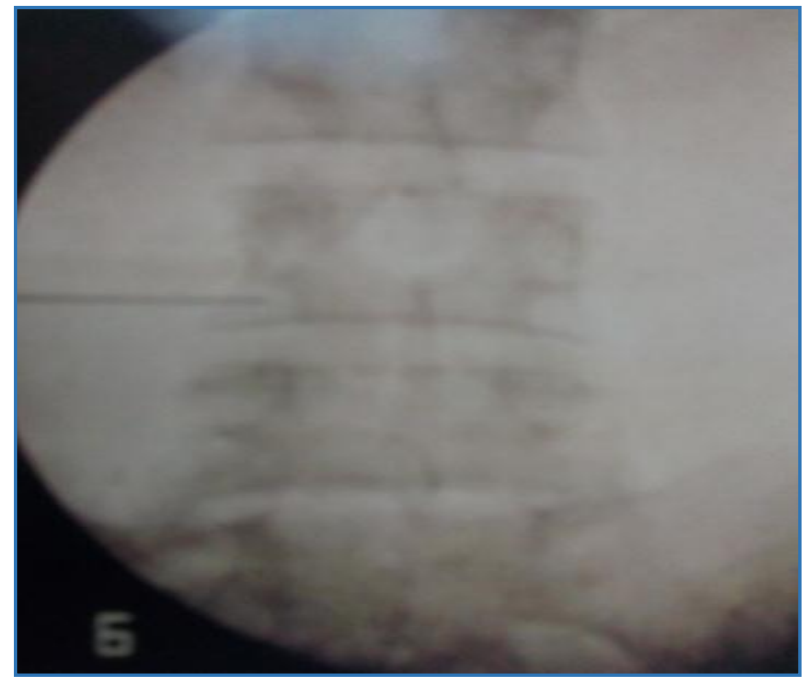

Fig. 1: Injection given between L4-L5 (AP view)

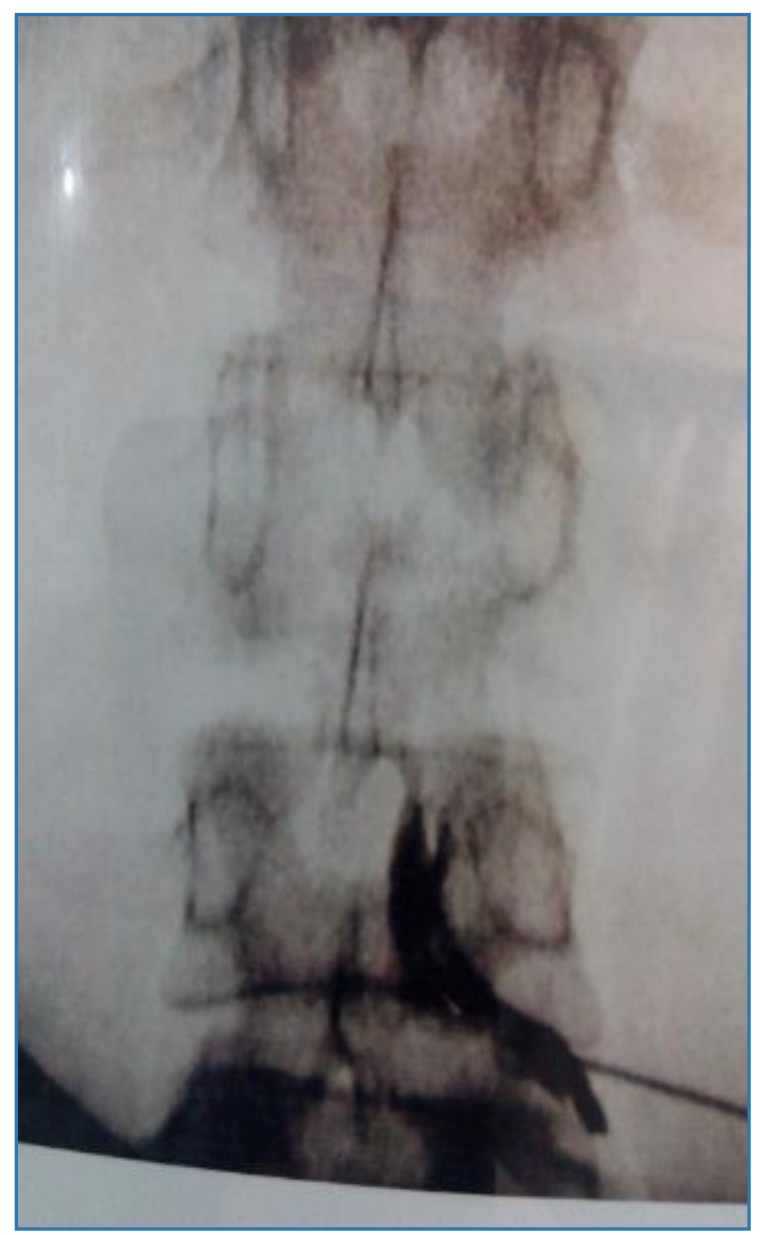

Fig. 2: After Injection of dye

After the procedure, the patients usually were observed for numbness in the dermatome supplied by the injected spinal nerve. Sometimes muscle weakness occurred in accordance with the innervations pattern.

All patients were put on a standardized program of physical therapy, which included procedures for local pain relief and reconditioning exercises for spinal muscle for at least 6 weeks after the procedure.

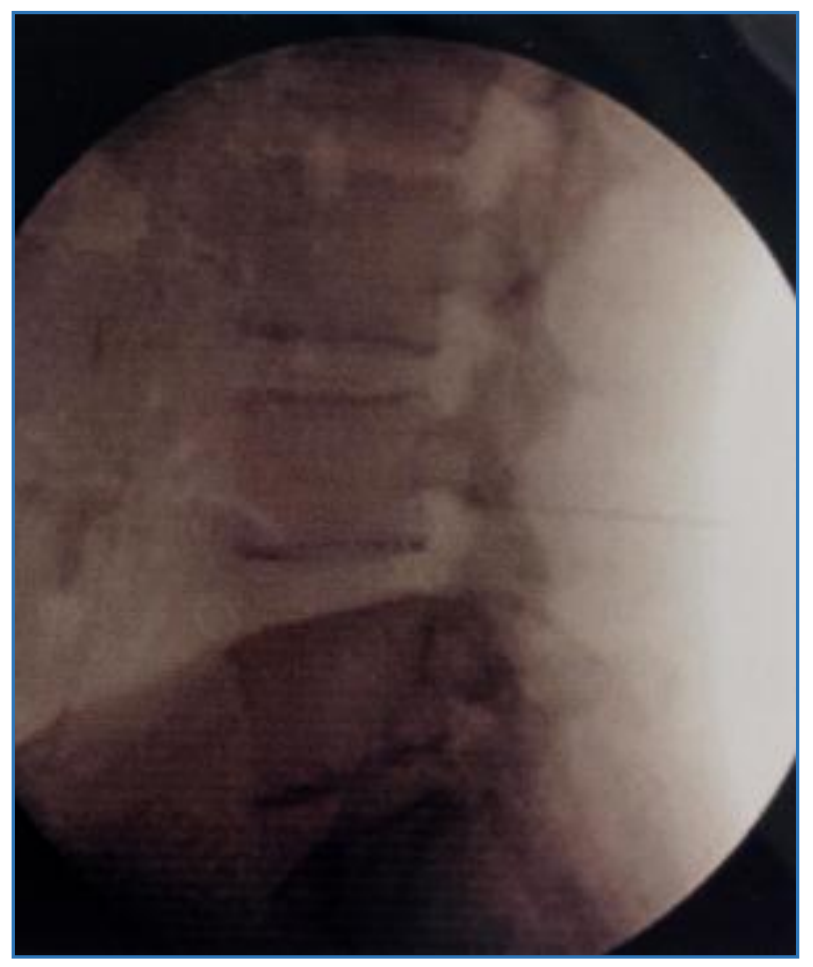

Fig. 3: Injection given between L4-L5 (Lateral view)

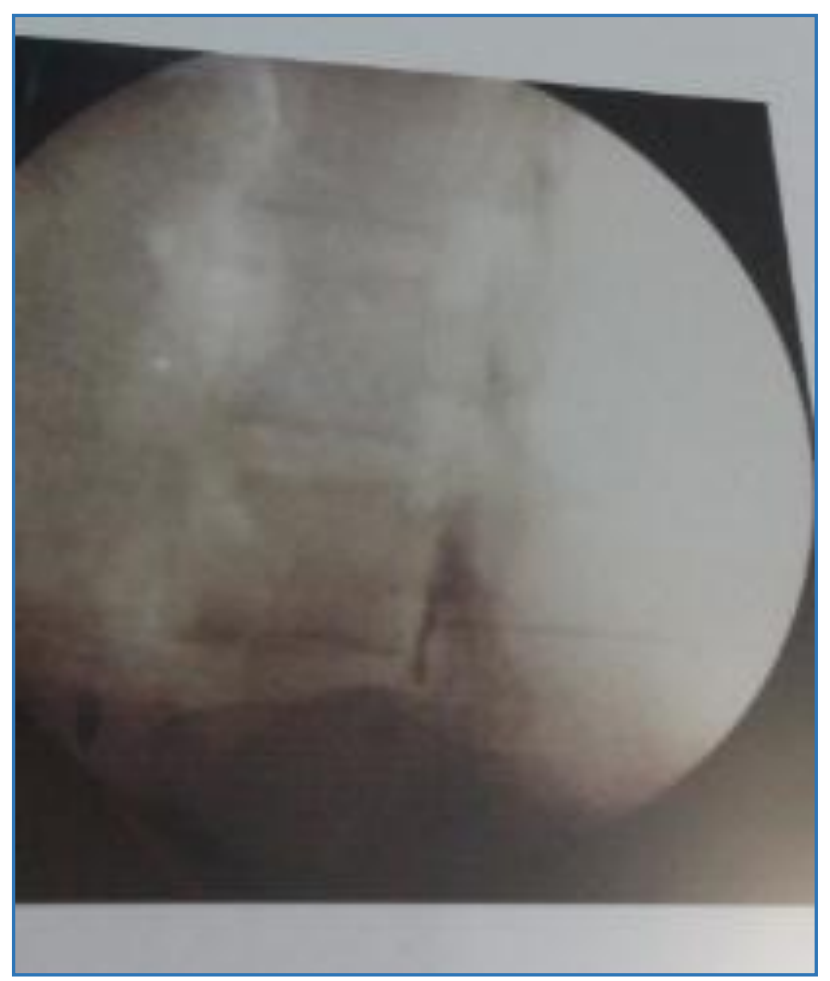

Fig. 4: After Injection of dye

\section{FOLLOWUP AND ASSESSMENT}

Followup of patients was done at 1-week, 1-month and 6 months following the procedure. Assessment was done on the basis of following criteria:- Findings based on clinical examination. -modified Oswestry low back pain disability index.15,16,17 -visual analogue score. -modified Macnab score. $15,16,17$ 


\section{DISCUSSION}

In our study, 100 patients were taken for TFESI in the age group of 20-60 years. The mean duration of low back pain with radiculopathy was 17 months.

There were a total of 53 males and 47 females, which is a male percentage of $53 \%$ and a female percentage of $47 \%$. This study shows that prevalence of low back pain with radiculopathy is more common in men because of their nonsedentary lifestyle in this part of the world as against the study of Hee Sung Jeong, et al. (2007), which shows female dominance (106 male and 133 females; mean age 49.8 years; range 13-82 years of age.). ${ }^{18}$

SLRT: The average pre-injection SLR was $59.20^{\circ}$. There was a significant improvement in all the patients post injection as average SLR went up to $85.35^{\circ}(\mathrm{p}<0.001)$, standard deviation pre-injection SLR was 9.96 and post injection SLR was 4.56 , hence it is proved that results following TFESI are excellent.

\section{Visual Analogue Score (Pain)}

The average pre-treatment score was 5.51 and post treatment showed significant improvement following the procedure with score coming down to $1.63(\mathrm{p}<0.001)$ and standard deviation pre-injection was 1.16 and post injection was 0.88 at the end of third followup at 3 months. These results are comparable with the studies of Vad VB, Bhat et al. (1976). ${ }^{12}$ who demonstrated successful outcome (Both pain radiation and improved function) in $84 \%$ of the patients. Another study by Ahadian, Farshad et al. shows that at the $12^{\text {th }}$ post injection week VAS scores declined to $26.6 \%$.

\section{Modified Oswestry low back pain disability questionnaire score (Functional disability)}

The average pre-treatment score was 32.12 patients with TFESI, which improved to 10.80 post treatment $(\mathrm{p}<0.001)$, standard deviation pre-injection was 3.05 and standard deviation post injection was 2.59 . This clearly shows that these procedures improve the functional ability in a person significantly though there is not much difference between the first and the last followup. These findings are statistically significant. The findings are comparable to J. Tudell RA (2001) who reported results of SNRB in 36 patients on the basis of various parameters on pain relief. Our study compares with Kawu, et al. (2012) who reported pre-injection ODI mean 31.2 and post injection ODI mean $12.2(\mathrm{p}<0.01) .{ }^{19}$

\section{Modified Macnab Scale}

Approximately $63 \%$ of the patients had excellent, $33 \%$ good, $3 \%$ fair and $1 \%$ poor outcomes based on modified Macnab criteria.

\section{COMPLICATIONS}

Vasovagal reactions occurred in 4\% patients. The observation is in consonance with David J. Kennedy, et al. (2013). ${ }^{20}$ who reported an incidence of $3.6 \%$ vasovagal reaction in their study. Another study done by Karaman, et al. reported a vasovagal reaction in $8.7 \%$ patients. ${ }^{21}$

Intravascular injection in 5\% patients. The complication rate compares favourably well with the study of Karaman $\mathrm{H}$, et al. (7.4\% intravascular injection rate in their study). ${ }^{21}$
Disc entry was noted in $2 \%$ patients, which was noticed by the spread of medications to structures outside of the intended epidural target. Finn and Case, et al. (2005). ${ }^{22}$ recounted a case of disc entry as a complication of transforaminal injection. Hong JH, et al. (2013).23 published the overall incidence of Intradiscal injection to be $2.4 \%$.

Nerve trauma, manifested by severe pain was noted in $3 \%$ patients. Bogduk et al. (2004) also reported this complication in their study without mentioning the percentage. ${ }^{24}$

\section{CONCLUSION}

Transforaminal epidural steroid injections with long acting anaesthetic is an excellent form of conservative treatment in management of low backache with radicular pain. It is relatively safe, simple, economical and shortens the time of recovery from severe pain, avoids risks and complications of surgery and also avoids long periods of bed rest.

\section{REFERENCES}

1. Frymoyer JW, Cats Baril WL. An overview of the incidences and costs of low back pain. Orthop Clin North Am 1991;22:263-271.

2. Vad VB, Bhat AL, Lutz GE, et al. Transforaminal epidural steroid injections in lumbosacral radiculopathy. Spine 2002;27:11-16.

3. Silbergleit R, Mehta BA, Sanders WP, et al. Imaging guided injection techniques with fluoroscopy and CT for spinal pain management. Radiographics 2001;21:927-942.

4. McLain RF, Frymoyer JW, Weisel SW, et al. Lumbar disc disease. The adult and paediatric spine, 3rd edition Philadelphia, PA: Lippincott Williams and Wilkins, 2004;929-944.

5. Sitzman BT, Fenton DS, Czervionke LF (eds). Epidural Injection. Image guided spine intervention. Philadelphia, Saunders, 2003;99-126.

6. Cohen SP, Bicket MC, Jamison D, et al. Epidural steroids: a comprehensive, evidence based review. Reg Anaesth Pain Med 2013;38:175-200.

7. Manchikanti L, Abdi S, Atluri S, et al. An update of comprehensive evidence based guidelines for interventional techniques in chronic spinal pain. Part II: Guidance and recommendations. Pain Physician 2013;16:S49-283.

8. Koc Z, Ozcakir S, Sivrioglu K, et al. Effectiveness of physical therapy and epidural steroid injections in lumbar spinal stenosis. Spine (Phila Pa 1976) 2009;34:985-9.

9. Luijsterburg PA, Verhagen AP, Ostelo RW, et al. Effectiveness of conservative treatments for lumbosacral radicular syndrome: a systemic review. Eur Spine J 2007;16:881-99.

10. Boswell MV, Trescott AM, Datta S, et al. American society of interventional pain physicians. Interventional techniques: evidence based practice guidelines in the management of chronic spinal pain. Pain Physician 2007;10:7-111.

11. Lutz GE, Vad B, Wisneski RJ, et al. Fluoroscopic transforaminal lumbar epidural steroids: an outcome study. Arch Phys Med Rehabil 1998;79:1362-6. 
12. Vad V, Bhat A, Lutz G, et al. Transforaminal epidural steroid injections in lumbosacral radiculopathy: a prospective randomised study. Spine 2002;27:11-6.

13. Riew KD, Yin Y, Gilula L, et al. The effect of nerve root injections on the need for operative treatment of lumbar radicular pain. A prospective, randomised, controlled, double blind study. J Bone Joint Am 2000;82A:1589-93.

14. Derby R, Bogduk N, Kine G. Precision percutaneous blocking procedures for localising spinal pain. Part II: The lumbar neuraxial compartment. Pain digest 1993;3:175-188.

15. Fairbank JCT, Couper J, Davies JB. The Oswestry low back pain questionnaire. Physiotherapy 1980;66:271-273.

16. Jong Min Byun. The effects of a forceful transforaminal epidural steroid injection on radicular pain: Korean J Pain 2014 October; Vol 27, No.4; 334-338.

17. Warden V, Hurley AC, Volicer L. Development and psychometric evaluation of the pain assessment in advanced dementia (PAINAD) scale. Journal of American Medical Directors Association 2003;4:9-15.

18. Hee Sung Leong, et al. Effectiveness of transforaminal epidural steroid injection by using a preganglionic approach. Radiology Vol 245; Number 2 - Nov 2007; 245:55-90.
19. Kawu AA, et al. Epidural steroid injection in patients with lumbosacral radiculopathy in Abuja, Nigeria. J Neurosci Rural Pract 2012;3:121-5.

20. David J Kennedy, et al. (2013). Vasovagal rates in fluoroscopically guided interventional procedures: a study of over 8000 injections; Pain Med 2013 December; 14(12). doi:10.1111/pme.12241.

21. Haktan Karaman, Gonul Olmez Kavak, et al. The complications of transforaminal epidural steroid injections. Spine 36(13):E819-824. June.

22. Finn K, Case J. Disk entry: a complication of transforaminal epidural injection-a case report. Arch Phys Med Rehabil 2005;86:1489-91.

23. Hong JH, Kim SY, Huh B, et al. Analysis of inadvertent intradiscal and intravascular injection during lumbar transforaminal epidural steroid injections: a prospective study. Reg Anaesth Pain Med 2013;38:520-525.

24. Bogduk N. Lumbar Medial Branch Blocks. Practice guidelines for spinal diagnostic and treatment procedures. San Francisco: International Spine Intervention Society, 2004:47-65. 